\begin{tabular}{|ccc|}
\hline & ANNALES INSTITUTI SLAVICI \\
& UnIVERSITATIS DEBRECENIENSIS & \\
SLAVICA XLIX & 2020 & DEBRECEN \\
\hline
\end{tabular}

Марина ЛАРИОНОВА - Надежда ТРОПкинА

\title{
«ЧЕХОВСКАЯ ДЕКОРАЦИЯ»: «ВИШНЕВЫЙ САД» В РУССКОЙ ПОЭЗИИ XX - НАЧАЛА XXI ВЕКА*
}

\author{
"Chekhov's Stage Set»: \\ «The Cherry Orchard» in the Russian Poetry of the $20^{\text {th }}$-early $21^{\text {st }}$ Centuries
}

\begin{abstract}
Chekhov's text is one of the most significant constituents of the Russian poetry of the 20 th - early 21 st centuries. The one most frequently alluded to is the play by Chekhov «The Cherry Orchard». The play written at the break of historical epochs turns out to be in tunes with the times of another turning-point. This fact conditions the allusion to the Chekhov's text in a poem «The Young Poetry» by V. Kornilov. The main feature of the crucial time period in the poem is the category of freedom, unexpectedly granted during the historical turn and change. The key theme, which determines the historiosophical sense of the text, is a quotation from «The Cherry Orchard», a dialogue between Gaev and Fiers. I. Kabysh perceives the Chekhov's play both mythopoetically and symbolically in such poems as «How Niveous-White Everything Is in Russia Today! " and «The Snow Started to Fall Without Delays». She introduces a different time into the text, models the reality after the events described in «The Cherry Orchard» and interpreted by the author of the poem in the lower clef (as in «crumbled estate»). The loss of the Garden, its disintegration, the loss of entity, is a gradual, step by step, process - into dachas, then into dust; that is the way the motif of vanishing space and culture appears.
\end{abstract}

Keywords: Chekhov, "The Cherry Orchard», poetry, Kornilov, Kabysh

Активное обращение современных авторов к творчеству Чехова - очевидный факт, отмеченный многими исследователями. Так К.Д. Гордович пишет: «Современные писатели достаточно часто обращаются к мотивам и образам Чехова. Творческие задачи при этом решаются самые разные: изображение жизни сквозь призму наивного детского сознания; изображение обитателей "сумасшедшего дома", их восприятие окружающего мира как путь обнаружения не просто противоречий жизни, но абсурда и алогизма в ней и др.» [ГОРДОВич 2017: 122].

Чеховский пласт в современной прозе и драматургии исследован достаточно подробно. Менее детально изучено обращение к чеховским мотивам и образам в поэзии. Между тем Вл. Коробов во вступительной заметке к публикации стихотворной подборки о Чехове «Ах, зачем нет Чехова на свете!..» пишет: «Около 150 единиц хранения насчитывает картотека "Чехов в русской поэзии” Дома-музея А.П. Чехова в Ялте» [КОРОБОв 2009: 55].

Публикация подготовлена в рамках реализации ГЗ ЮНЦ РАН, проект № АААА-А19119011190182-8. 
Чеховский текст - одна из значительных составляющих русской поэзии конца XX - начала XXI века. Современную поэтическую чеховиану составляют произведения столь разных поэтов, как А. Кушнер, Ю. Левитанский, И. Бродский, Ю. Кублановский, Н. Глазков, Т. Кибиров, Б. Ахмадулина, С. Кекова, Б. Окуджава, О. Дозморов, и многих других. К числу наиболее частотных относится обращение к пьесе Чехова «Вишневый сад». В ряду многочисленных произведений, которые так или иначе содержатся отсылки к чеховскому тексту, отразились различные грани художественной семантики и поэтики пьесы «Вишневый сад». В нашей статье мы рассмотрим один семантический пласт интерпретации чеховской «закатной пьесы» на материале творчества двух поэтов разных поколений - В.Корнилова и И. Кабыш.

Значение заглавного образа пьесы «Вишневый сад» истолковывается в диапазоне от «символа дворянского быта» до «метафоры смены исторических эпох, где бы и на какой социальной почве эта смена ни происходила» [ПолоЦКАЯ 2003: 5]. Такой разброс интерпретаций предсказуем: в историческом и общекультурном контексте «Вишневый сад» дает широкий простор для различного рода творческих интерпретаций.

Закономерно, что сама чеховская пьеса, написанная на изломе исторических эпох, оказывается созвучной времени другого перелома, «смены вех» на ином историческом витке. Этим обусловлено обращение к чеховскому тексту в стихотворении В. Корнилова «Молодая поэзия»:

Поэзия молодая,

Тебя еще нет почти,

Но славу тебе воздали,

Не медля, твои вожди;

И те, лет кому семнадцать,

Кому восемнадцать зим,

Уверены: все - эрзацы,

И надо дерзать самим;

И надо смахнуть с насеста

Заевшихся стариков,

Преемственность, и наследство,

И прочую смерть стихов.

Тут сразу без сиволдая

Закружится голова.

Поэзия молодая,

Наверное, ты права. 
Но нынче поменьше к лире

Приставлено сторожей,

И ей одиноко в мире,

Свободнее и страшней.

И душу ободрить сиру

Пред волею и бедой

Навряд ли сейчас под силу

Поэзии молодой [КОРНИЛОВ 2004: 242-243].

В жанровом отношении текст представляет собой послание молодым поэтам, и в этом продолжение традиции русской классической литературы и поэзии Серебряного века. Стихотворение написано в 1987 г., когда и в жизни страны, и в литературной ситуации происходили бурные перемены. В. Корнилов, художник сложной и во многом драматичной судьбы, после многих лет отлученности от читателя вновь становится «разрешенным». О поэтическом языке Корнилова Н.В. Королева пишет: «Его стихи были просты и прямолинейны, без метафорических и иных прочих украшений, но покоряли своей удивительной, ясной и какой-то бесхитростной поэтичностью» [КОРОЛЕВА 2004: 248]. Поэзия Корнилова тяготеет к автологической речи, к намеренно культивируемой «безобразности». В стихотворении «Молодая поэзия» чеховское начало можно уловить уже в самой интонации беседы-раздумья, размышления и сомнения («Наверное, ты права»). Однако чеховский пласт в тексте глубже - он формирует важнейшую грань его семантики. Главной приметой переломного времени в стихотворении Корнилова оказывается категория свободы, нежданно дарованной в ходе исторического поворота. К этой категории Корнилов не раз обращается с своей лирике конца 1980-х гг. Яркий пример тому стихотворение, совпадающее по времени написания с текстом послания к молодой поэзии - «Свобода» (1987). Оба эти произведения составляют определенное смысловое единство, раскрывая разные грани сложного процесса, вызванного новой реальностью. В стихотворении «Свобода» в фокусе авторской рефлексии оказывается внутреннее ощущение лирического героя, которое прямо выражено в первой и последней строфе текста: «Не готов я к свободе» - «А пришла - не готов» [КОРнилОВ 2004: 231-232]. В стихотворении «Молодая поэзия» тема свободы осмысливается как самоощущение художника на историческом переломе. В строке, предшествующей финальной строфе, закономерно соединяются два слова: «свободнее и страшней». Поэт обретает свободу, но одновременно ощущает свое одиночество в мире, и это не романтическое самовосприятие художника, противостоящего толпе - это, напротив, осознание мессианской роли поэта, призванного спасти - ободрить - человеческую душу. И ключевым мотивом, определяющим историософский смысл текста, оказывается в стихотворении Корнилова цитата из «Вишневого сада» - диалог Гаева с Фирсом: 
Фирс. Перед несчастьем тоже было: и сова кричала, и самовар гудел бесперечь.

Гаев. Перед каким несчастьем?

Фирс. Перед волей [ЧЕХОВ 1978: 224].

Это обращение к образу Фирса из «Вишневого сада» - знаменательно. В целом ряде исследований Фирс рассматривается как главная фигура чеховской пьесы - характерно название статьи «"Вишневый сад” - пьеса про Фирса? О новых смыслах классического образа» [Химич 2010]. В репликах Фирса о прошлом («В прежнее время, лет сорок-пятьдесят назад, вишню сушили, мочили $<\ldots>$ Денег было! И сушеная вишня тогда была мягкая, сочная, сладкая, душистая... Способ тогда знали... [ЧЕХОВ 1978: 206]; «Мужики при господах, господа при мужиках, а теперь все враздробь, не поймешь ничего» [ЧЕХОВ 1978: 222] срабатывает механизм мифологических народных рассказов о прошлой жизни, записанных и исследованных фольклористами только в наши дни: «Рассказы о прошлом и настоящем конструируют идеальное прошлое, обладающее такими признаками, как нормированность (упорядоченность) жизни, наличие веры, мистического опыта и знания, единства людей и т.П.» [БАРАНОВА 2000: 67-68]. Элементы ламентации («Жизнь-то прошла, словно и не жил» [ЧЕХОв 1978: 254], словесного высказывания, содержащего жалобы на жизнь [RIES 1997: 84]), как бы замыкают круг, завершают жизненный цикл. В стихотворении В. Корнилова актуализирован историософский и мифопоэтический потенциал образа чеховского героя: слова Фирса о прошлом в стихотворении поэта конца XX века оборачиваются на изломе времен сбывшимся пророчеством.

Символическое значение образа сада в чеховской пьесе складывается из нескольких мифологем: дерево, вишня, сад, цветение. Образ вишневого сада в его исторической ретроспективе находит одно из самых ярких воплощений в поэтическом творчестве И. Кабыш.

Одно из первых таких обращений - стихотворение «Как в России-то нынче бело!..»:

Как в России-то нынче бело! двор что чеховская декорация: завело, залило, замело:

место дикое, дикая нация.

Мы страшны, потому что грешны:

раскромсали именье на дачи, на пыль: и всё бы нам власть старшины сатаны: у, рабы, азиатчина!..

Что за тени в терновых венцах?

Что за время: кончина ли? роды ли? Дом проели мы на леденцах, за похлёбку имение продали. 
И, ненужные днесь никому, мы, как Фирс, заколочены заживо, позабытые Богом в дому, во саду, где порубки не зажили, в деревянной России, в шкафу: нам спастись, что верблюду в игольное влезть ушко: вот и бьёмся в строфу, как в оконце четырехугольное [КАБыш 2008: 74].

Уже в первой строфе стихотворения возникает двойное пространство: историческое и сценическое: «Бело $<. . .>$ чеховская декорация» напрямую перекликается с семантикой белого цвета, доминирующего в чеховской пьесе и в одежде персонажей (Лопахин в белой жилетке, белая комната, Фирс в белом жилете и в белых перчатках, Шарлотта Ивановна в белом платье, покойная мама Раневской вспоминается в белом платье, белые руки Дуняши, Прохожий в белой рубашке, белый бильярдный шар Гаева), и в самом образе сада: «Сад весь белый» - реплика Гаева, «Весь, весь белый! О, сад мой!», «белое деревцо», «Белые массы цветов»- Раневской. Уже экспозиционной ремаркой чеховской пьесы имплицитно вводится белый цвет: «Уже май, цветут вишневые деревья, но в саду холодно, утренник. Окна в комнате закрыты» [ЧЕХОВ 1978: 197]. Отталкиваясь от сюжета чеховской пьесы, И. Кабыш вводит в текст иное время, моделирует реальность, которая последовала за событиями, которые описываются в «Вишневом саде» и интерпретируются автором стихотворения в сниженном ключе («раскромсали именье»). Утрата Сада, его распадение, утрата целостности, движется поэтапно - на дачи, потом на пыль - возникает мотив исчезающего пространства. Этот мотив заложен в самой чеховской пьесе, с словах Ани: «Вишневый сад продан, его уже нет» [ЧЕХОВ 1978: 241]. Упоминание пыли в строках Кабыш - это и реализация действия, связанного с глаголом «распылить»: измельчить, и рассеять. И таким же образом исчезает усадебный мир - мир прежней России, утрачивается его культура, превращаясь в свою противоположность «место дикое, дикая нация». Характерна в этом контексте перекличка с другим стихотворением И. Кабыш - «А снег пошел без проволочек...». Начинающееся прямой отсылкой с Пастернаку, в последней строфе оно содержит обращение к чеховскому тексту:

Как входят в толщи атмосферы, откуда нет пути назад, в судьбу как входят, кроме веры, безо всего. Себя на скверы кроша, чтоб стал вишнёвый сад [КАБыш 2008: 197].

Вишневый сад в финале стихотворения воплощает идею утраченной цельности бытия, скверы - своего рода реинкарнация образа дач, на которые распадается, распыляется сад. 
Определение «дикая» в контексте стихотворения «Как в России-то нынче бело!..» может прочитывается как знак возвращения пространства и людей, его населяющих, к некоему первобытному, рабскому состоянию - его знаком становится «азиатчина». Не случайно в стихотворении возникает и образ сатаны. Ю.М. Фаткуллина отмечает: «Последняя пьеса драматурга раскрывает различные схемы искушения демоническим героем, демонстрирует демонических героев, относящихся к различным культурным традициям» [ФАТКУЛЛинА 2013: 32]. Развитием этого мотива в стихотворении Кабыш становится отсылка к библейскому тексту, которая предстает в стихотворении в прямом сопоставлении с цитатой из «Вишневого сада»: «Дом проели мы на леденцах, за похлёбку имение продали» [КАБЫШ 2008: 74]. В стихотворении библейский и евангельский контекст расширяется и дополняется строкой «ненужные днесь никому» (курсив наш. - М.Л., Н.Т.), строками «нам спастись, что верблюду в игольное / влезть ушко». Строки с анафорическим началом - авторское вопрошание - обращены к «шествию теней» в терновых венцах. Сама ситуация крушения мира, шествия, настойчиво повторяющихся вопросов перекликается и с поэмой Блока «Двенадцать». Образы третьей строфы стихотворения полигенетичны: они восходят и к евангельскому контексту, и к строкам из поэмы В. Маяковского «Облако в штанах»:

Где глаз людей обрывается куцый, главой голодных орд, в терновом венце революций грядет шестнадцатый год [МАякОВский 1978: 238].

Ключевым в стихотворении оказывается образ Фирса («мы, как Фирс, заколочены заживо») - именно ему, заколоченному в России, в дому, в шкафу, который оборачивается гробом (здесь, возможно, отсылка и непосредственно к тексту «Вишневого сада» и образу шкафа, о чем пишет Ю.В. Доманский [ДоМАНСКИЙ 2015], и к роману И. Шмелева «Солнце мертвых» с его образом шкафа-гроба), уподоблен образ авторского я / мы, для которого единственное возможное спасение - поэзия, творчество. Знаменательна в стихотворении антиномия смерти - рождения, столь органичная для пьесы «Вишневый сад».

К теме судьбы России в продолжение и полемике с чеховской традицией И. Кабыш обращается и в стихотворении

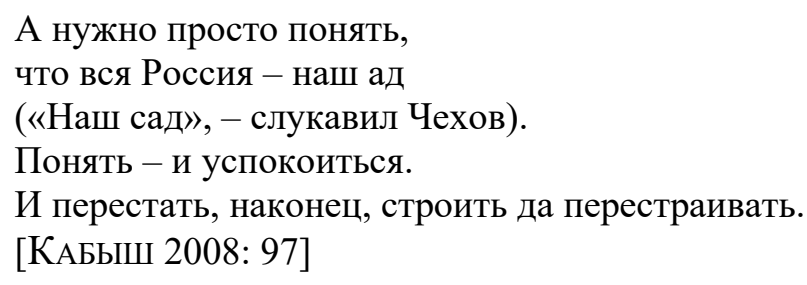

Эти строки Кабыш интерпретирует Л. Аннинский, напрямую связывая их с темой судьбы России у Чехова и у поэта XXI века: «Слово “Россия” включает 
в словесной сети сверхнапряжение. Понимая это, героиня нас как бы успокаивает, приводя в свидетели такого остроумца, как Чехов» [Аннинский 2008: 20].

Итак, события, происходящие в последней пьесе Чехова стали миромоделирующими в поэзии В. Корнилова и И. Кабыш, поэтов другой эпохи, а вишневый сад - символом перелома в истории и человеческом сознании. Однако исторический комплекс мотивов, к которым обращаются поэты, далеко не исчерпывает смысл чеховского текста в русской лирике второй половины XX - начала XXI века. Не менее существенна интерпретация вишневого сада как воплощения универсума. В работе «К гипотетическим контекстам "Вишневого сада"》 отмечается: «Художественное пространство "Вишневого сада", в силу необходимости помещенное "в комнате с тремя стенами", подразумевает образ мира как мифологического музыкального инструмента и мира как сферы, невидимой “осью” которой и является лопнувшая струна» [ЛощилОВ - ТыщЕНКО 2014: 239]. В этом контексте знаменательно обращение к чеховской пьесе в лирике Б. Ахмадулиной и И. Лиснянской, но это тема дальнейшего исследования.

\section{Литература}

Аннинский 2008: Аннинский, Л. Невеста. В кн.: Кабыш И. Невеста без места. Москва: Время, 5-24.

БАРАНОВА 2000: Баранова, В.В. Рассказы современных крестьян о прошлом и настояшем. В кн.: Традиции в фольклоре и литературе (под ред. Лурье, М.Л.). СанктПетербург: 66-76.

Гордович 2019: Гордович, К.Д. Обращение современных авторов к мотивам «Вишневого сада». В кн.: Чеховские чтения в Ялте. Вып. 23: Изучение чеховского наследия на рубеже веков: взгляд из XXI столетия (под ред. Пернацкой, О.О.). Симферополь: ИТ «АРИАЛ», 122-132.

ДомАнский 2015: Доманский, Ю.В. Шкаф в «Вишневом саде». В кн.: Последняя пьеса Чехова в искусстве XX-XXI веков. Коллективная монография (под ред. Головачева, А.Г., Гульченко, В.В., Доманский, Ю.В.). Москва: ГЦТМ им. А.А. Бахрушина, 49-57.

КАБыш 2008: Кабыш, И. Невеста без места. Москва: Время.

Корнилов 2004: Корнилов, В. Собрание сочинений: В 2 т. Т.1. Стихи и поэмы. Москва: Хроникер.

Коробов 2009: Коробов, Вл. «Ах, зачем нет Чехова на свете!..». Вступ. заметка к публикации стихов о Чехове // Нева. № 12, 4-24.

КоРОЛЕВА 2004: Королева, Н. О тех, кто в памяти и в сердце. Воспоминания о Владимире Корнилове // Вопросы литературы. 2004/6: 246-261.

Лощилов - Тыщенко 2014: Лощилов, И.Е., Тыщенко, В.П. К гипотетическим контекстам «Вишневого сада». В кн: «Учености плоды»: к 70-летию профессора Ю.В. Шатина. Новосибирск: Издательство НГПУ, 219-255.

МАяковский 1978: Маяковский, В.В. Собрание сочинений: В 12 т. Т.1. Москва: Правда.

ПолОцКАЯ 2003: Полоцкая, Э.А. «Вишневый сад»: Жизнь во времени. Москва: Наука. 
ФАткуллинА 2013: Фаткуллина, Ю.М. Комедия А.П. Чехова «Вишневый сад» в аспекте феномена демонического // От текста к контексту. 1: 29-33.

Химич 2010: Химич, В.В. «Вишневый сад» - пьеса про Фирса? О новых смыслах классического образа. Известия Уральского государственного университета, Сер. Гуманитарные науки. 1 (72) 26-35.

ЧЕхов 1978: Чехов, А.П. Полное собрание сочинений и писем: В 30 т. Сочинения: В 18 т. Т.13. Москва: Наука.

REIS 1997: Reis, N. Russian talk: culture and conversation during perestroika. Ithaka \& London, Cornell University Press.

Марина ЛАРИОНОВА

Федеральный исследовательский центр южный научный центр российской академии наук

Ростов-на-Дону Россия ssc-ras@ssc-ras.russc-ras@ssc-ras.ru

ORCID ID: 0000-0002-2955-2621

Надежда ТРОПкинА

Волгоградский государственный социально-педагогический университет

Волгоград, Россия

literature@vspu.ru

ORCID ID: 0000-0003-0720-8069 